\title{
Nurses as Street Level Bureaucrats: Experiences from Diabetes Care Nurses in Kuwait
}

\author{
Muna Alshammari ${ }^{1}$, Sylivia Nalubega ${ }^{2}$ \\ ${ }^{1}$ College of Nursing, Public Authority for Applied Education and Training, Shuwaikh Educational Region, Kuwait \\ ${ }^{2}$ Department of Nursing, School of Health Sciences, Soroti University, Soroti, Uganda \\ Email: alshammari_pinky@msn.com, syliviaogwang@yahoo.com
}

How to cite this paper: Alshammari, $M$. and Nalubega, S. (2021) Nurses as Street Level Bureaucrats: Experiences from Diabetes Care Nurses in Kuwait. Open Journal of Nursing, 11, 315-319. https://doi.org/10.4236/ojn.2021.115028

Received: April 3, 2021

Accepted: May 15, 2021

Published: May 18, 2021

Copyright () 2021 by author(s) and Scientific Research Publishing Inc. This work is licensed under the Creative Commons Attribution International License (CC BY 4.0).

http://creativecommons.org/licenses/by/4.0/

\begin{abstract}
Street-level bureaucrats are described as public service workers who interact directly with citizens in the course of their work and who have substantial discretion in the execution of their work. This article is a reflection of the primary author's doctoral research experience, which investigated the role of nurses in caring for long-term diabetes patients in two selected hospitals in Kuwait. Nurses working in diabetes care in Kuwait were reported to operate under difficult conditions and utilized the tool of discretion to provide patient care, hence were exemplary street-level bureaucrats.
\end{abstract}

\section{Keywords}

Nurses, Street-Level Bureaucrats, Diabetes, Kuwait

\section{Introduction}

Street-level bureaucracy (SLB) is a sociological theory by Lipsky that seeks to explain the working practices and beliefs of frontline workers in public services and the ways in which they utilize public policy to guide their daily operations. The term street-level bureaucrats is used to describe public service workers who interact directly with citizens in the course of their jobs, and who have substantial discretion in the execution of their work [1]. In many settings, street-level bureaucrats are referred to as civil servants. These workers support governments to implement policies and while doing so may have some discretion on how the particular policies are implemented [2]. Street-level bureaucrats act as liaisons between government policy-makers and the public and these civil servants implement policy decisions made by senior authorities. Examples of street-level 
bureaucrats are police officers, teachers, general practitioners, and social workers [3].

While implementing their work, it is alleged that street-level bureaucrats encounter numerous challenges attributed to the limited amount of time and resources available to interact and provide services. As a result, they may make decisions that do not favor the citizens [3]. Besides, policy guidelines and regulations may not necessarily align with the specific needs of the citizens prompting the street-level bureaucrats to develop coping mechanisms to address the particular situation. Hence, street-level bureaucrats have a level of discretion/autonomy during their practice [2] [4].

\section{Background}

This article is a reflection from the primary author's doctoral research experience, which investigated the role of nurses in caring for long-term diabetes patients in two selected hospitals in Kuwait. These hospitals were selected as they were the only ones at the time offering specialised diabetes care in Kuwait. In her professional experience, she noticed that nurses invent their own ways of performing tasks they are required and expected to accomplish, such as addressing particular patients' needs. She also noted that these nurses often experienced a lack of organizational support which compromised patient care. In his description, Lipsky [5] clarifies that street level bureaucrats tend to operate under the pressure of routine and brittle organizations which may not offer a supportive environment and consequently may result in workers failing to meet clients' needs. Nurses working in diabetes care in Kuwait work as frontline staff to address the care needs of diabetes patients and advocate for them [6] hence fit within Lipsy's description of street-level bureaucrats.

Due to the bureaucrat's behavior toward policy preferences, the role of street-level bureaucrats may however remain ambiguous as policy actors often have conflicting notions of what they seek to implement [7]. This may bring confusion and contradictions during role performance and as a result, discretion becomes a useful tool in enabling street-level bureaucrats to perform their work. Discretion is a term closely related to the operations of street-level bureaucrats and describes the extent of the freedom that public service workers can exercise in a specific context and the factors that give rise to this freedom [2]. Lipsky [1] comments that discretion provides an opportunity for street-level bureaucrats to intervene on behalf of their clients thereby providing flexibility in performing their duties. Diabetic nurses in Kuwait exercised discretion in various ways as elaborated further in this article.

\section{Discussion}

\subsection{The Application of Diabetes Care Guidelines}

While providing diabetes care, nurses in Alshammari's study had two options: 1) to stick to the guidelines which are too broad and do not specify what their role 
is or 2) to stick to the guidelines which are too narrow that do not cover all what nurses perform in diabetes care [6]. Therefore, nurses encountered two issues: 1) they became frustrated as they did not know if their performance is outside the scope of their practice or 2) they played more than what they are expected to do. The theory of street-level bureaucracy could be a model that includes the implementation of new guidelines specifically designed for nurses involved in providing diabetes care. Nurses are expected to follow guidelines which are established in evidence-based practice; however, depending on operational circumstances, nurses can operate under the umbrella of street-level bureaucrats and exercise discretion by modifying or creating their own guidelines that are applicable to their individual scopes of practice and settings.

\subsection{Providing Diabetes Care}

Nursing care for type 2 diabetes may vary across countries as a result of differences in healthcare systems and the way in which nursing is organised and practiced. In Kuwait, the role of diabetes nursing care is not well developed and lacks clarity which leaves nurses ambiguous regarding the role. Despite the current practice in which the top-down approach dominates, diabetes care nurses in $\mathrm{Ku}$ wait have tailored their own practice to meet patients' needs [6]. According to Kosar and Schachter [7], street-level bureaucrats play vital roles in influencing policy implementation through their attitudes and values. Diabetes is a chronic illness that requires carefully planned and long term care. The absence of a well-defined role for nurses has caused lack of support, alongside underutilisation of the role [8]. In order to provide the best care for their patients, nurses will, within the limits of their professional roles, adapt guidelines within legal and medical limits to support their patients. Therefore, nurses can be considered, at times, to adopt the role of street-level bureaucrats in order to provide quality care to their patients. In Kuwait, nurses revealed their contributions to the local guidelines by adjusting the recommendations stated in those guidelines, in order to overcome barriers and make decisions about the use of resources and facilities [6]. Those decisions were able to ease their interactions with patients, as well as helped the nurses to become effective in their practice. The nurses were considered as frontline staff in diabetes clinics; in most cases meeting patients before other medical personnel. These actions by nurses have impacted on the recent direction of diabetes care and therefore, Lipsky's theory serves to make some sense of the struggles Kuwait nurses experience in finding and using suitable resources that are designated for them [1].

\subsection{Bureaucracy and the Diabetes Care Role}

Top-down and bottom-up strategies are both needed in order to create a balanced working environment in diabetes care, in which healthcare providers, including nurses, are motivated to work efficiently and effectively. Lipsky suggests that in order to improve policies, an understanding of the context of nurses' work is essential [4]. The guidelines currently available for diabetes care in $\mathrm{Ku}$ - 
wait specify what the different interventions for diabetes care are, but do not specify "who should do what". While in other settings such as the UK practice allows diabetes nurses to be involved in evaluating and examining the already established guidelines and to determine which of these will accomplish a given set of goals [9], Kuwait generally adopts a top down, physician-led hierarchy approach, in which medical staff are controlling the diabetes care model that is offered [6]. This approach is likely to undermine patient care.

\subsection{Discretion and the Diabetes Care Role}

Street-level bureaucrats have discretion because the nature of service provision calls for human judgment that cannot be programmed and for which machines cannot substitute [2]. There is an interrelation between discretion and rules. Rules specify the duties and obligations of officials while discretion gives them freedom to act. The international diabetes care guidelines [10] include generic recommendations, resulting in nurses performing multiple tasks that might not be relevant to the diabetes care role, and this lack of focus and relevance might impact on the diabetes nurses' level of performance and quality of care provided to patients. However, Langfred and Moye suggest that the accomplishment of multiple functions increases a competent individual's autonomy and levels of interdependency [11]. Such autonomy and levels of interdependency are exemplified by the Kuwait diabetes nurses who were involved in updating guidelines informing their roles as active healthcare professionals [6]. Diabetes care nurses in Kuwait reported working under stressful, unclear and sometimes unfavorable circumstances that affected patient care. As such, diabetes nurses used their power of discretion as street level bureaucrats, to align their care to prevailing hospital circumstances. Lipsky presented the matter of policy change as a dynamic and collaborative process which needs individual input in order to recognise each individual's work environment so as to understand why policies do not necessarily achieve expected outcomes [4]. A significant discovery in Alshammari's study was that diabetes care nurses in Kuwait were found to be "policy changers" in the context of contributing to and being part of updating their guidelines [6].

\section{Conclusion}

This article has discussed how nurses working in diabetes care in Kuwait are exemplary street-level bureaucrats, who take on the responsibility of frontline diabetes care staff. These nurses generally work in conditions that are not encouraging or motivating to contribute to providing quality care and utilize the tool of discretion to execute their care role. Our article provides novel insights regarding the role of diabetes nurses in Kuwait and how this role is shaped by the sociological theory of street-level bureaucracy.

\section{Conflicts of Interest}

The authors declare no conflicts of interest regarding the publication of this paper. 


\section{References}

[1] Lipsky, M. (1980) Street-Level Bureaucracy: Dilemmas of the Individual Ipublic Services. Russell Sage Foundation, New York.

[2] Johannessen, L.E.F. (2019) Negotiated Discretion: Redressing the Neglect of Negotiation in "Street-Level Bureaucracy". Symbolic Interaction, 42, 513-538. https://doi.org/10.1002/symb.451

[3] Tummers, L. and Bekkers, V. (2013) Policy Implementation, Street-Level Bureaucracy, and the Importance of Discretion. Public Management Review, 16, 527-547. https://doi.org/10.1080/14719037.2013.841978

[4] Lipsky, M. (2010) Street-Level Bureaucracy Dilemmas of the Individual in Public Service. Russell Sage Foundation, New York.

[5] Lipsky, M. (2010) Street-Level Bureaucracy: Dilemmas of the Individual in Public Service. American Political Science Review, 76, 1-275.

[6] Alshammari, M. (2018) The Role of Nurses in Diabetes Care and the Impact of the Different Approaches of Nurses' Role on Patients Perceived Quality of Nursing Care: Two Case Studies from the UK and Kuwait. University of Nottingham, Nottingham. https://doi.org/10.35248/2155-6156.19.10.821

[7] Kosar, K.R. (2011) Street Level-Bureaucracy: The Dilemmas Endure. Public Administration Review, 71, 299-302. https://doi.org/10.1111/j.1540-6210.2011.02342.x

[8] Bloomer, M.J. and Cross, W.M. (2011) An Exploration of the Role and Scope of the Clinical Nurse Consultant (CNC) in a Metropolitan Health Service. Collegian, 18, 61-69. https://doi.org/10.1016/j.colegn.2010.09.002

[9] Alshammari, M. (2020) Diabetes Treatment Guidelines and Nurses' Adherence to Them: A Case of the UK and Kuwait. Journal of Nursing and Healthcare Research, 4, 1-12. https://doi.org/10.23880/NHIJ-16000214

[10] International Diabetes Federation (IDF) (2013) IDF Diabetes Atlas. International Diabetes Federation, Brussels.

[11] Langfred, C.W. and Moye, N.A. (2004) Effects of Task Autonomy on Performance: An Extended Model Considering Motivational, Informational, and Structural Mechanisms. Journal of Applied Psychology, 89, 934-945.

https://doi.org/10.1037/0021-9010.89.6.934 